\title{
Evaluasi jumlah saluran akar gigi premolar pertama atas menggunakan teknik radiografi periapikal pararel dan Cone Beam Computed Tomography
}

\author{
Sandy Pamadya ${ }^{1 *}$, Mirza Aryanto $^{2}$, Nurani Hayati ${ }^{2}$, Johannes Dhartono ${ }^{1}$
}

\begin{abstract}

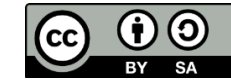

This work is licensed under a Creative Commons Attribution 4.0 which permits use, distribution and reproduction, provided that the original work is properly cited,
the use is non-commercial and no modifications or adaptations are made.
and

Objectives: Maxillary and mandibular first and also to test the accuracy of periapical premolars are amongst the teeth that has a risk to radiographs in detecting the number of root canals caries and needed to be treated. These teeth were of maxillary first premolar teeth compared to CBCT varied in term of root and root canal amount. A radiographs. successful root canal treatment in premolar teeth is highly dependent on the identification of the number and shape of root canals according to Vertucci. Radiographs are still the main choice in helping dentists establish an adequate diagnosis and treatment plan for root canal treatment. Conventional radiographs produce two-dimensional images which often cause difficulties in interpreting the resulting radiograph images. Modern imaging modalities such as CBCT can be used to produce a more accurate image. The aim of this study was to determine whether there is a difference in the number of root canals of maxillary first premolar teeth displayed on periapical radiographs and CBCT

Materials and Methods: This research was experimented by performing periapical radiological examinations and CBCT on 50 maxillary premolar teeth samples, then evaluating the number of visible root canals.

Results: The results showed that there was a significant difference in the number of root canals seen on the periapical radiograph and CBCT.

Conclusion: CBCT radiographs have the advantage of detecting the number of root canals of maxillary premolars more accurately than periapical radiographs.

Keywords: Cone beam computed tomography, periapical radiograph, maxillary first premolar

Cite this article: Pamadya S, Aryanto M, Hayati N, Dhartono J. Evaluasi jumlah saluran akar gigi premolar pertama atas menggunakan teknik radiografi periapikal pararel dan Cone Beam Computed Tomography. Jurnal Radiologi Dentomaksilofasial Indonesia 2021;5(1)7-12. https://doi.org/10.32793/jrdi.v5i1.671
\end{abstract}

${ }^{1}$ Department of Dentomaxillofacial Radiology, Faculty of Dentistry, Universitas Prof. Dr. Moestopo (Beragama), Jakarta, Indonesia 12330

${ }^{2}$ Department of Conservative Dentistry Faculty of Dentistry, Universitas Prof. Dr. Moestopo (Beragama), Jakarta, Indonesia 12330

*Correspondence to:

Sandy Pamadya

囚sandypamadyadrg@gmail.com

Received on: February 2021

Revised on: March 2021

Accepted on: April 2021

\section{INTRODUCTION}

Riset Kesehatan Dasar Gigi dan Mulut rencana perawatan. Seiring perkembangan (Riskesdas Gilut) 2018 untuk pertama kalinya teknologi dan ilmu kedokteran gigi, semakin banyak melibatkan langsung dokter gigi di bawah naungan jenis pemeriksaan radiologi yang cukup akurat. Pengurus Besar Persatuan Dokter Gigi Indonesia (PB Radiograf konvensional menggunakan film analog PDGI). Hasilnya ditemukan bahwa penduduk ataupun reseptor digital menghasilkan gambar dua Indonesia yang mengalami masalah gigi dan mulut dimensi dari objek tiga dimensi. Hasilnya struktur sebanyak $57,6 \%$, sayangnya tidak dijabarkan jenis kelainan atau masalah gigi dan mulutnya. Berdasarkan hasil Riskesdas tahun 2013, prevalens nasional indeks DMF-T adalah 4.6, termasuk kategori tinggi menurut WHO. ${ }^{1,2}$ Kurangnya inisiatif untuk menjaga maupun melakukan perawatan gig dan mulut sedari dini menyebabkan masalah gigi dan mulut yang berkelanjutan di masa dewasa, yang pada akhirnya gigi yang bermasalah tidak dapat direstorasi langsung tanpa melalui perawatan saluran akar.

Perawatan saluran akar merupakan jenis tindakan yang umum dilakukan oleh baik dokter gig umum maupun spesialis konservasi gigi, tergantung tingkat kesulitannya. Pemeriksaan penunjang radiologi masih menjadi pilihan utama dalam membantu dokter gigi menegakkan diagnosis dan anatomi di sekeliling gigi saling tumpang tindih dan sering menyebabkan kesulitan dalam menginterpretasi gambaran radiograf yang dihasilkan. Modalitas pencitraan radiologi terbaru dapat digunakan agar dapat menghasilkan gambaran yang lebih akurat serta dapat mewakili struktur 3 dimensi tanpa khawatir saling tumpang tindih. Cone-beam Computed Tomography 3D atau CBCT $3 D$ adalah salah satu modalitas pencitraan yang banyak digunakan di kalangan dokter gigi. ${ }^{3}$

Gigi premolar merupakan gigi yang cukup sering mengalami karies sehingga diperlukan perawatan saluran akar. Gigi premolar rahang atas maupun rahang bawah banyak ditemukan bervariasi dari mulai jumlah akar maupun jumlah saluran akarnya. Vertucci meneliti dari masing-masing 400 buah gigi premolar pertama dan kedua rahang bawah, 
terdapat $74 \%$ gigi premolar pertama rahang bawah memiliki satu saluran akar, 25,5\% memiliki dua saluran akar, dan 0,5\% memiliki tiga saluran akar. Sedangkan pada gigi premolar kedua rahang bawah, 97,5\% memiliki satu saluran akar dan 2,5\% memiliki dua saluran akar. ${ }^{4}$ Penelitian lain oleh Kartal (1998) menuliskan insidensi gigi premolar pertama rahang atas yang memiliki satu saluran akar adalah $8,66 \%$, di mana sebanyak $89,64 \%$ dar total 600 buah gigi premolar pertama rahang atas yang diteliti memiliki dua saluran akar. ${ }^{5}$ Perawatan saluran akar memerlukan pemeriksaan penunjang radiologi untuk mendukung diagnosis dan rencana perawatan yang akurat. Penelitian terdahulu oleh Giudice dkk. mengenai akurasi radiograf periapikal dan CBCT menunjukkan bahwa pada radiograf periapikal gambaran yang dihasilkan memiliki keterbatasan dan pada CBCT jumlah saluran akar dan lesi yang tampak lebih jelas. ${ }^{6}$

Keberhasilan perawatan saluran akar pada gig premolar sangat bergantung pada identifikasi jumlah dan bentuk saluran akar sesuai klasifikasi yang sudah ada. Pemeriksaan radiologi denta berperan penting dalam mendeteksi morfologi dan jumlah saluran akar, sehingga rencana perawatan dapat dibuat dengan baik. Radiograf periapika sebagai pilihan utama dengan segala keterbatasannya masih banyak digunakan oleh dokter gigi di seluruh dunia, sedangkan $C B C T$ yang termasuk ke dalam teknologi pencitraan modern dengan segala kelebihannya masih jarang digunakan terutama di Indonesia. Penelitian in bertujuan untuk menggambarkan apakah terdapat perbedaan dari jumlah saluran akar yang tampak pada radiograf periapikal dan $C B C T$ gigi premola pertama rahang atas.

\section{MATERIALS AND METHODS}

Penelitian ini dilakukan dengan jenis penelitian deskriptif, yaitu dengan melakukan pemeriksaan radiologi dengan teknik radiografi periapikal dan CBCT pada 50 buah sampel gigi premolar pertama rahang atas, lalu menyajikan data dalam tabel. Populasi penelitian ini adalah semua gigi yang sudah dicabut dan telah digunakan dalam kegiatan praktikum mata kuliah Konservasi Gigi di FKG UPDM (B). Sampel penelitian adalah gigi premolar pertama rahang atas yang telah dicabut dan telah digunakan dalam kegiatan praktikum mata kuliah Konservasi Gigi di FKG UPDM (B) sebanyak 50 buah, dengan kriteria inklusi berupa gigi tersedia dalam kondisi yang baik, tidak terdapat karies yang sangat luas yang menyebabkan mahkota hilang lebih dari setengah, dan kriteria eksklusi meliputi gigi yang sudah dilakukan obturasi saluran akar.

Penelitian dilakukan di instalasi Radiologi Dental FKG UPDM (B) dan laboratorium klinik Pramita Pasar Minggu. Preparat gigi premolar pertama rahang atas yang sudah masuk kriteria inklusi ditempel ke film periapikal untuk kemudian dilakukan teknik radiografi periapikal paralel (Gambar 1). Pesawat sinar-X yang digunakan adalah pesawat sinar- $X$ intraoral merk Belmont tipe Phot-X II Mounted, dengan pengaturan tegangan listrik di $60 \mathrm{kV}$, arus listrik di $7 \mathrm{~mA}$ dan waktu eksposur 0,2 detik. Hasil radiograf periapikal untuk seluruh gigi (total 25 buah radiograf untuk 50 buah gigi) kemudian diamati

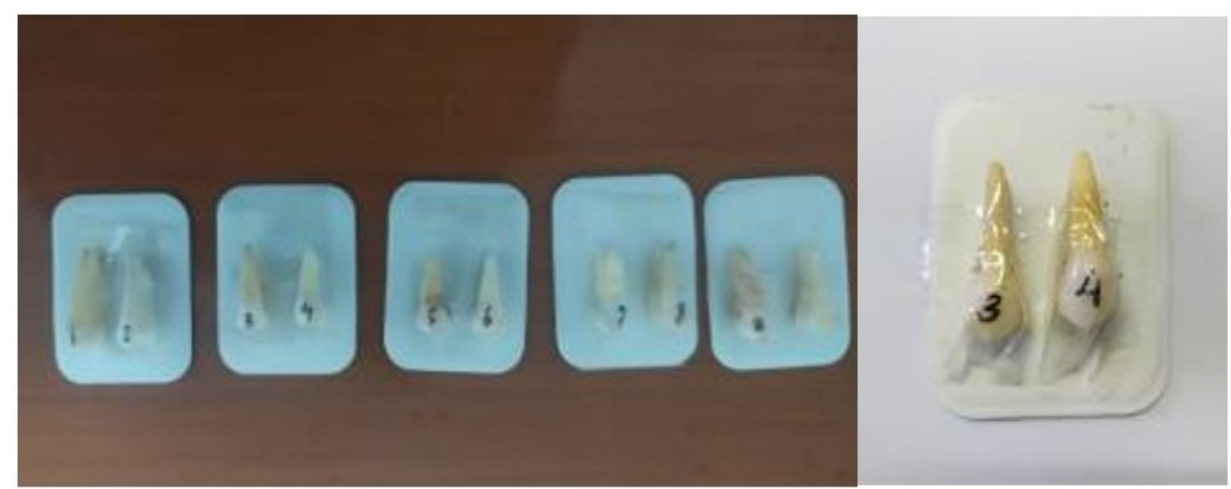

Gambar 1. Peletakan gigi pada film yang direkatkan menggunakan isolasi

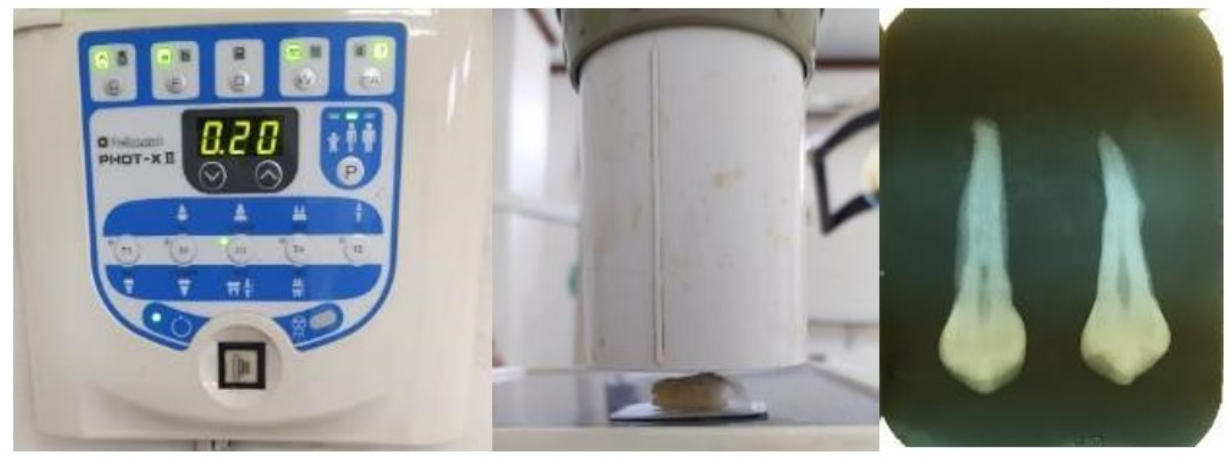

Gambar 2. Teknik radiografi periapikal paralel dan hasil radiograf sampel gigi premolar pertama rahang atas setelah proses digitalisasi menggunakan light viewer dan kamera 

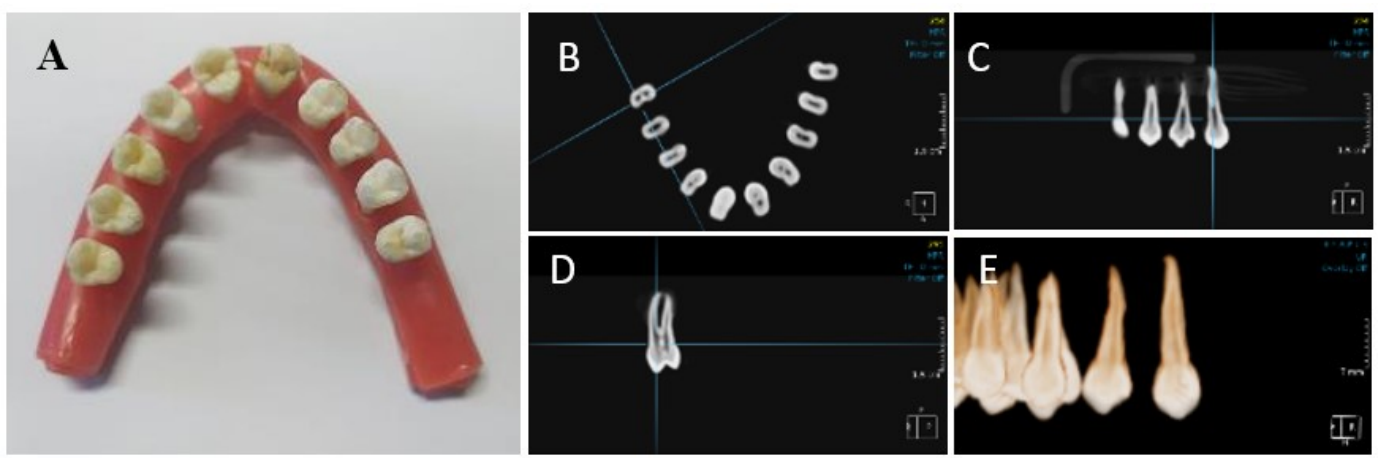

Gambar 3. (A) Rangkaian gigi pada lilin base plate; (B) Tampilan perangkat lunak CBCT untuk mengevaluasi umlah saluran akar dari potongan aksial, (C) sagital, (D) koronal, dan (E) rekonstruksi 3 dimensi.

Tabel 1. Hasil evaluasi jumlah saluran akar pada radiograf periapikal dan CBCT

\begin{tabular}{ccc}
\hline JENIS RADIOGRAF & TAMPAK GAMBARAN 1 AKAR & TAMPAK GAMBARAN 2 AKAR \\
\hline Periapikal & 50 radiograf & - \\
CBCT & - & 50 radiograf \\
\hline
\end{tabular}

secara langsung jumlah saluran akar yang tampak dan dicatat berdasarkan nomor yang telah diberikan. Digitalisasi dilakukan menggunakan light viewer dan kamera ponsel untuk kepentingan dokumentasi (Gambar 2). Digitalisasi maksudnya adalah membuat data digital dari sebuah gambar analog (film periapikal yang dihasilkan) agar data yang didapat lebih mudah untuk disimpan dan mencegah kerusakan akibat perlakuan, serta mempermudah pengamatan menggunakan computer karena data berupa file gambar yang dapat dengan mudah diperbesar atau diperkecil dan diatur tingkat kecerahannya.

\section{RESULTS}

Hasil evaluasi jumlah saluran akar gigi premolar pertama rahang atas pada radiograf periapikal dan CBCT dijabarkan pada tabel 1 .

\section{DISCUSSION}

Hasil dari evaluasi jumlah saluran akar sampel gigi premolar rahang atas pada radiograf periapikal dan CBCT menunjukkan perbedaan yang cukup siginifikan, dimana mayoritas hasil pengamatan gigi premolar pertama rahang atas pada radiograf periapikal tampak hanya memiliki tampilan 1 buah saluran akar, sedangkan pengamatan pada hasil radiograf $C B C T$ menunjukkan gambaran 2 buah saluran akar di semua sampel gigi premolar rahang atas (Gambar 4 dan 5).

Hasil pengamatan jumlah saluran akar gigi premolar rahang atas menunjukkan keterbatasan dari radiograf periapikal konvensional 2 dimensi, dimana hampir semua hasil pengamatan menghasilkan nilai 1 buah saluran akar. Keterbatasan ini dikarenakan teknik radiografi periapikal paralel menghasilkan gambaran 2 dimensi dari struktur 3 dimensi, dan hanya menampilkan gambaran dari 1 bidang saja yaitu bidang sagital, sehingga apabila ada 2 buah objek yang sejajar, gambarannya akan saling tumpang tindih pada radiograf dan akan membiaskan interpretasi.

Contoh lain pada sampel nomor 7 meskipun menunjukkan gambaran 2 buah akar pada radiograf periapikal, setelah melalui proses enhancement gambar dengan mengatur kontras dan tingkat kecerahan, memperbesar gambar, di-inverse, hingga mempertajam gambar menggunakan perangkat lunak khusus pencitraan radiologi dental, tetap hanya tampak 1 buah saluran akar. Radiograf $C B C T$ sampel nomor 7 dengan jelas menunjukkan gambaran 2 saluran akar (Gambar 6). Semua sampel diperlakukan sama dan dievaluasi menggunakan perangkat lunak yang sama untuk masing-masing jenis radiograf.

Ketika melakukan teknik radiografi periapikal paralel untuk gigi premolar pertama rahang atas, secara anatomis akar bukal dan pal atal gigi premolar pertama rahang atas memiliki posisi yang cenderung sejajar, sehingga pada radiograf kemungkinan terjadinya gambaran yang tumpang tindih lebih besar. Terkadang kedua akar tersebut sangat divergen baik ke arah buko-palatal maupun mesial-distal, sehingga ada kemungkinan kecil sebagian akar tidak saling tumpang tindih, sehingga dapat dilihat cukup jelas jumlahnya ada 2 buah. Teknik radiografi periapikal paralel untuk gigi premolar pertama rahang atas bisa dimodifikasi untuk dapat melihat akar bukal dan palatal dengan cukup jelas. Teknik radiografi periapikal modifikasi SLOB (Same Lingual Opposite Buccal) dapat digunakan untuk melihat 2 buah objek yang saling tumpang tindih agar tampak cukup jelas pada hasil radiograf. ${ }^{7}$ Kalibrasi posisi sampel dan cone pesawat sinar-X yang digunakan diperlukan untuk menghindari kesalahan akibat kelalaian operator dalam menempatkan model sampel dan cone 


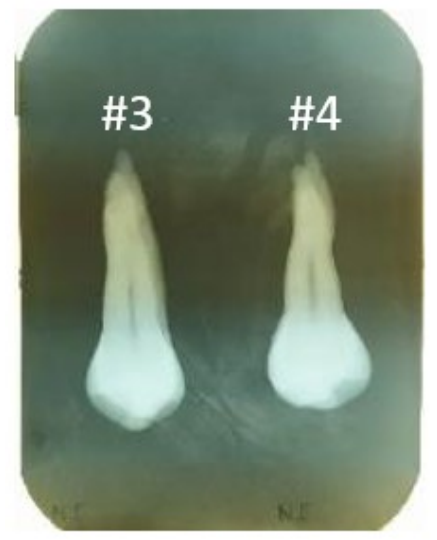

Gambar 4. Radiograf periapikal gigi premolar pertama rahang atas nomor sampel 3 dan 4 . Perhatikan gambaran sampel nomor 4, meskipun tampak 2 akar namun saluran akar hanya tampak seperti berjumlah 1 buah.

pesawat sinar-X sehingga tidak paralel, dengan tujuan agar semua sampel mendapatkan perlakuan yang homogen.

Penelitian sebelumnya dengan populasi etnis Turki menyebutkan bahwa mayoritas gigi premolar pertama rahang atas yang diperiksa memiliki 2 saluran akar, dan pada penelitian dengan populasi etnis Tionghoa dan Spanyol hasilnya menunjukkan bahwa mayoritas gigi premolar pertama rahang atas memiliki 2 saluran akar. ${ }^{8,9,10}$

Radiograf periapikal dapat memberikan informasi yang kurang baik terkait morfologi dan jumlah saluran akar. Radiograf ini menunjukkan 1 hingga 3 gigi yang bersebelahan dalam 1 regio. Teknik radiografi periapikal ada dua jenis, yaitu teknik periapikal paralel dan teknik periapikal bisektris. Kebanyakan klinisi lebih memilih teknik periapikal paralel karena memberikan hasil distorsi yang lebih sedikit. Teknik periapikal paralel merupakan teknik yang paling sesuai untuk pencitraan digital. Salah satu alasannya adalah karena kebanyakan sensor digital lebih rentan untuk rusak, sehingga untuk menghindari tertekuk atau rusak akibat jari pasien, digunakan film holder untuk teknik paralel. Selain itu juga untuk meminimalisir kemungkinan terjadinya distorsi, tekni k paralel lebih ideal karena posisi film dengan objek cenderung sejajar. Konfigurasi anatomi (seperti palatum dan dasar mulut) yang sempit ataupun dangkal dapat menyulitkan teknik periapikal paralel. $^{11}$ Radiograf $C B C T$ dapat memberikan informasi tambahan yang lebih detail dan akurat, yang tidak bisa terlihat pada radiograf periapikal, mulai dari anatomi yang tumpang tindih, jumlah saluran akar gigi, posisi konstriksi apikal, keterlibatan akar gigi dengan struktur anatomi lain seperti kanalis mandibula dan sinus maksilaris, hingga garis fraktur yang tidak terdeteksi.

Penelitian ini masih memiliki banyak sekali kekurangan, antara lain adalah dari jumlah sampel yang kurang banyak, kurang jumlah observer, dan kualitas radiograf periapikal konvensional yang kurang baik. Penggunaan teknik radiografi periapikal konvensional menggunakan film yang perlu diproses secara kimiawi menyebabkan adanya kemungkinan kualitas radiograf yang menurun apabila saat pemrosesan kurang baik. Pemrosesan di kamar gelap dapat dipengaruhi oleh kualitas larutan developer dan fixer itu sendiri serta cara pemrosesan film tersebut oleh operator. Selain itu proses digitalisasi juga mempengaruhi hasil gambaran yang dapat diamati pada perangkat lunak.

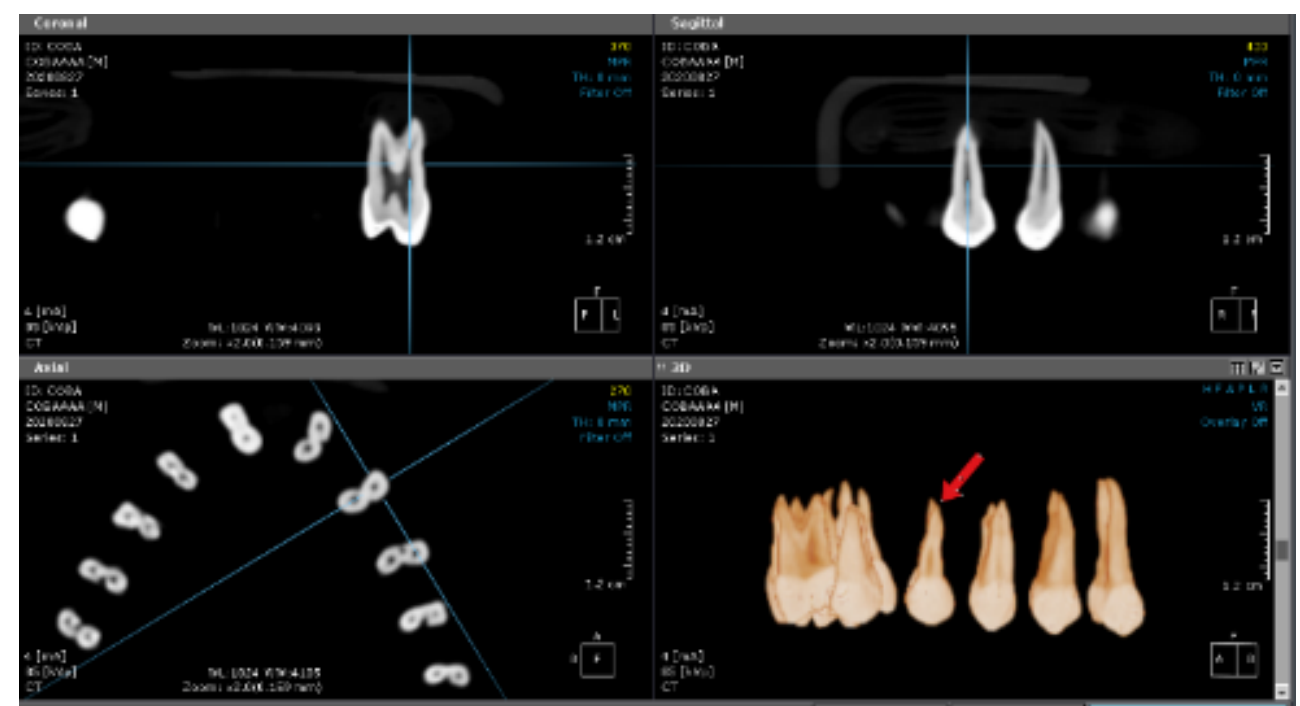

Gambar 5. Radiograf CBCT gigi premolar pertama rahang atas nomor sampel 4.

Tampak dengan jelas gambaran saluran akar berjumlah 2 buah dari potongan aksial dan koronal. 


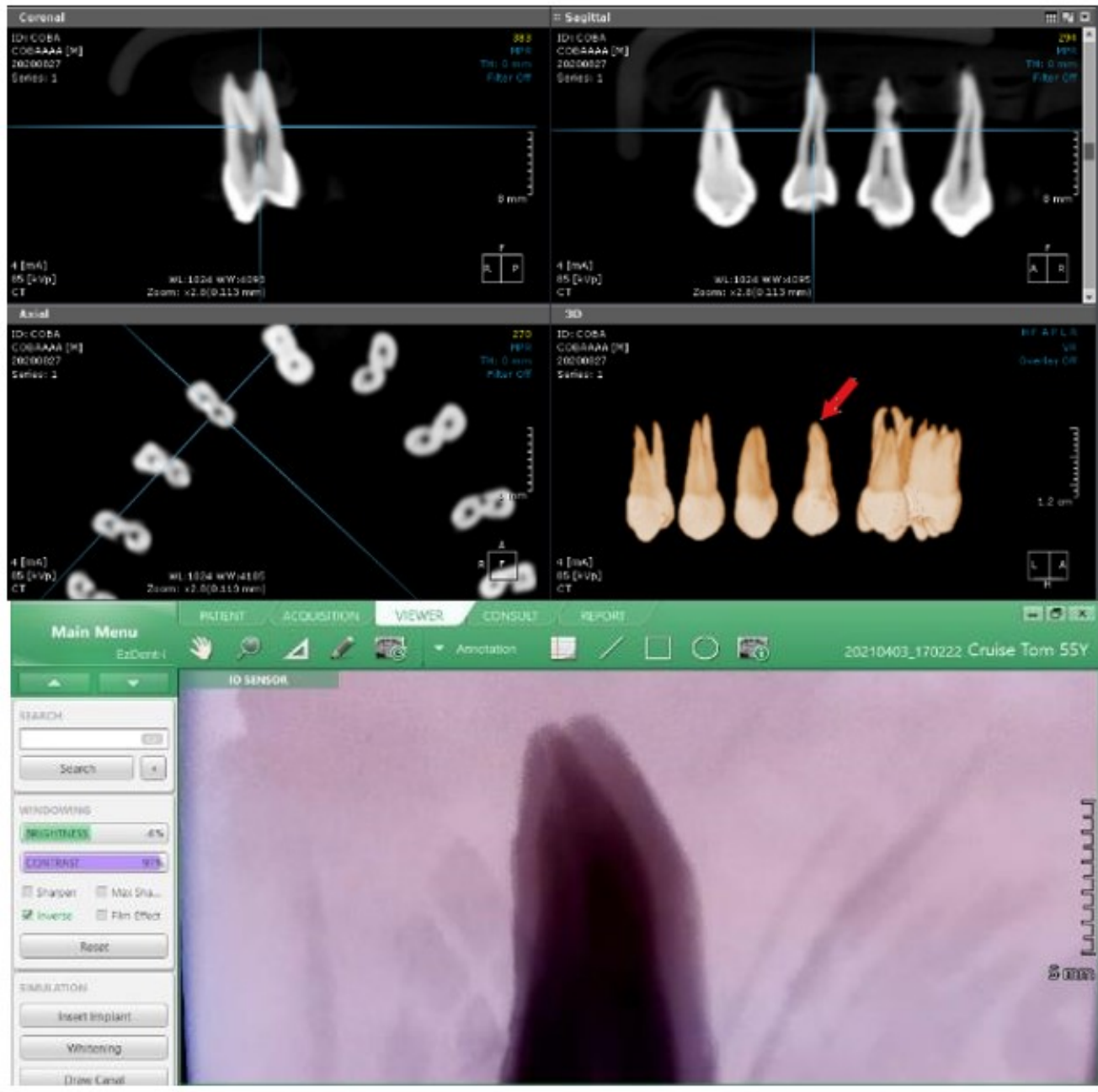

Gambar 6. Gambaran sampel nomor 7 pada radiograf $C B C T$, tampak jelas jumlah saluran akar berjumlah 2 buah (ATAS); melalui image enhancement tetap tidak tampak gambaran 2 saluran akar pada radiograf periapikal (BAWAH).

\section{CONCLUSION}

Evaluasi jumlah saluran akar gigi premolar pertama rahang atas dapat dilakukan melalui pemeriksaan radiologi. Teknik yang dapat dilakukan di antaranya adalah teknik radiografi periapikal paralel dan CBCT. Teknik radiografi periapikal paralel sangat mudah untuk dilakukan, murah, dan dosis radiasi yang dipaparkan sangat kecil (kurang lebih 0,003 $\mu \mathrm{Sv}$ ), namun memilik keterbatasan seperti gambaran akar yang tumpang tindih, sehingga menyulitkan dokter gigi untuk menginterpretasi jumlah saluran akar secara tepat. Selain itu pada pasien dengan refleks muntah yang cukup tinggi atau pasien trismus, teknik radiografi periapikal paralel sulit untuk dilakukan. Teknik radiografi $C B C T$ memiliki kelebihan yaitu menghasilkan gambaran dari 3 bidang ortogonal aksial, sagital dan koronal, sehingga dapat melihat morfologi akar dengan lebih jelas serta mendeteksi jumlah saluran akar lebih akurat dibandingkan radiograf periapikal. CBCT dengan segala kelebihannya juga memiliki kekurangan, yaitu harganya yang sangat mahal dan dosis radiasi yang lebih besar apabila dibandingkan dengan teknik radiografi periapikal.

\section{ACKNOWLEDGMENTS}

None.

\section{FOOTNOTES}

All authors have no potential conflict of interest to declare for this article. This article does not contain any studies with human or animal subjects performed by the any of the authors.

\section{REFERENCES}

1. Badan Penelitian dan Pengembangan Kesehatan Kementrian Kesehatan Republik Indonesia. Hasil Utama Riskesdas 2018 (Dikutip pada 22 April 2021). Dapat diakses di: http:// www.depkes.go.id/resources/download/info-terkini/hasilriskesdas-2018.pdf.

2. Badan Penelitian dan Pengembangan Kesehatan Kementrian Kesehatan Republik Indonesia. Riset Kesehatan Dasar 2013 (Dikutip pada 22 April 2021). Dapat diakses di: http:// www.depkes.go.id/resources/download/general/Hasil Riskesdas 2013.pdf

3. Deepak BS, Subash TS, Narmatha VJ, Anamika T, Snehil TK, Nandini DB. Imaging Techniques in Endodontics: An Overview. J Clin Imaging Sci. 2012; 2: 13

4. Bansal R, Hegde S, Astekar MS. Classification of Root Canal Configurations: A Review and a New Proposal of Nomenclature System for Root Canal Configuration. Journal 
of Clinical and Diagnostic Research 2018;12(5): ZE01-ZE05.

5. Kartal N, Ozçelik B, Cimilli H. Root canal morphology of maxillary premolars. J Endod. 1998 Jun;24(6):417-9.

6. Lo Giudice R, Nicita F, Puleio F, Alibrandi A, Cervino G, Lizio AS, Pantaleo G. Accuracy of Periapical Radiography and CBCT in Endodontic Evaluation. Int J Dent. 2018;2514243.

7. Whaites E, Drage N. Essentials of Dental Radiography and Radiology 5th Edition. London: Churchill Livingstone-Elsevier; 2013

8. Ok E, Altunsoy M, Nur BG, Aglarci OS, Çolak M, Güngör E. A cone-beam computed tomography study of root canal morphology of maxillary and mandibular premolars in a Turkish population. Acta Odontol Scand. 2014 Nov;72(8):701

9. Yang H, Tian C, Li G, Yang L, Han X, Wang Y. A Cone-beam Computed Tomography Study of the Root Canal Morphology of Mandibular First Premolars and the Location of Root Canal Orofices and Apical Foramina in a Chinese Subpopulation. Endod 2013;39(4):435-8.

10. Llena C, Fernandez J, Ortolani PS, Forner L. Cone-beam Computed Tomography Analysis of Root and Canal Morphology of Mandibular Premolars in a Spanish Population. Imaging Science in Dentistry 2014;44(3):221-7.

11. White SC, Pharoah MJ. Oral Radiology Principles and Interpretation 7th Edition. St. Louis: Mosby-Elsevier; 2014. 